\title{
Combined Type 2 Diabetes and Ischemic Heart Disease: Double Jeopardy
}

\author{
Per Hildebrandt Jens Faber \\ Department of Cardiology and Endocrinology, H:S Frederiksberg Hospital, Frederiksberg-Copenhagen, Denmark
}

Type 2 diabetes increases the risk of coronary heart disease by a factor of 2-4. Haffner et al. [1] demonstrated that the 7-year mortality among type 2 diabetics without established ischemic heart disease (IHD) was similar to that of nondiabetics who had experienced a prior myocardial infarction (MI). The combination of type 2 diabetes and IHD further increased mortality by a factor of 2 [1]. Other long-term post-MI studies have demonstrated an approximately double mortality rate in diabetics versus nondiabetics [2].

The poor prognosis in diabetes is probably mainly due to both the high frequency of risk factors for IHD as well as more widespread coronary artery disease in diabetics, as also demonstrated in two articles in this issue of Heart $\operatorname{Drug}[3,4]$.

Conventional pharmacological treatment modalities, such as fibrinolysis, ASA, statins, beta-blockers and ACE inhibitors, have proven their efficacy in high-risk patients with diabetes, IHD, or both, and a general pattern is that for any given treatment the effect is greater in diabetics than in nondiabetics, i.e. numbers needed to treat are smaller among diabetics. Despite this fact, diabetics are in general treated to a lesser extent than nondiabetics [2,5]. This might simply be because physicians do not realize the severity of the diabetic disease, and because of prob-

\begin{tabular}{ll}
\hline KARGER & ( 2001 S. Karger AG, Basel \\
1422-9528/01/0013-0129\$17.50/0 \\
$\begin{array}{l}\text { Fax +4161306 12 34 } \\
\text { E-Mail karger@karger.ch } \\
\text { www.karger.com }\end{array}$ & $\begin{array}{l}\text { Accessible online at: } \\
\text { www.karger.com/journals/hed }\end{array}$
\end{tabular}

lems with compliance in these patients due to the many drugs prescribed.

In case of an acute MI, the Diabetes and Insulin-Glucose Infusion in Acute Myocardial Infarction I (DIGAMI I) study [6] suggested a beneficial effect on survival of acute glucose-insulin infusion in diabetics. This hypothesis is now being tested prospectively in the larger, ongoing DIGAMI II study, which also focuses on long-term glycemic control.

The beneficial effect of prolonged good glycemic control on the development of IHD in diabetics has been a matter of controversy. In large prospective trials, both in type 1 diabetics - Diabetes Control and Complications Trial (DCCT) [7] - and type 2 diabetics - United Kingdom Prospective Diabetes Study (UKPDS) [8] - good glycemic control tended to, but did not conclusively demonstrate a beneficial effect on the development of cardiovascular disease (CVD). However, in the UKPDS trial in type 2 diabetics, the patients were at low risk of CVD, and established CVD at entry was an exclusion criterion. In contrast, in the follow-up of the Kumamoto trial [9] good glycemic control in type 2 diabetics conclusively demonstrated reduced events of CVD, and in the UKPDS a subgroup of overweight patients demonstrated a quite substantial benefit from metformin treatment on the devel-
Per Hildebrandt
Department of Cardiology and Endocrinology
H:S Frederiksberg Hospital
DK-2000 Frederiksberg-Copenhagen (Denmark)
Tel. +45 3816 4360, Fax +45 3816 4369, E-Mail ph@fh.hosp.dk 
opment of CVD [10]. Of particular interest, the UKPDS trial demonstrated no adverse effects of insulin or sulfonylureas (SU) on the development of CVD [8]. It has otherwise been argued that glucose-lowering treatment increases the risk of mortality from CVD, insulin being atherogenic by itself [11], and SU reducing preconditioning in the ischemic heart [12].

In the present issue of Heart Drug, Hasdai et al. [3, 4] extract data on the outcome of percutaneous transluminal coronary angioplasty (PTCA) from an impressively large register from the Mayo Clinic. They find that diabetics treated with insulin have an approximately $60 \%$ higher risk of death or MI than those treated with oral agents or just diet. However, this is probably not due to insulin per se, but to the fact that these patients have more advanced diabetic disease, with more complications, especially of macrovascular type, which was indeed the case. The type of diabetes was not given, nor was the duration of disease or the degree of metabolic control (HbA1c). However, the majority of these patients most likely were type 2 diabetics on insulin. Five to ten percent of type 2 diabetics develop secondary therapeutic failure per year, and many of these end up on insulin, i.e., the fact that these patients were on insulin indicated longer duration of the disease, and thus probably more advanced disease. Nevertheless, the data are important from a clinical point of view, since they identify a group of diabetics with a particularly high risk of complications/death due to invasive therapy for IHD.

The type of invasive therapy - coronary artery bypass graft (CABG) or PTCA with or without stent - selected for the diabetic patients with IHD has been a matter of debate. In general diabetics should be offered the same treatment modality as nondiabetics, but on the basis of several recent studies and most impressively by the BARI I trial (although a posthoc analysis) [13], it emerges that diabetics offered PTCA have a much higher mortality than those offered CABG, particularly if the patients had a $\mathrm{Q}$ wave infarction [14]. This difference seems more moderate if the patients suffered a non-Q wave infarction. The reason for the poor prognosis using PTCA is complex, but it might be due to an inappropriate intimal hyperplasia after PTCA induced by the diabetic state [15]. Whether stenting is better than conventional balloon angioplasty is not clear. However, stenting does not obviate accelerated restenosis in diabetes [6]. In the article by Hasdai et al. [3] reported in this issue, the diabetic patients submitted for PTCA had an almost two-fold inhospital mortality, and an almost double mortality rate during long-term follow-up. As proposed by the authors, the adverse prognosis is probably not directly related to the procedure itself, but more likely owing to the more extensive coronary artery disease as well as to the less complete revascularization achieved during intervention. These findings could explain the results of a better outcome after CABG than PTCA in the Bypass Angioplasty Revascularization Investigation I (BARI I) trial.

Of interest is a new class of drugs, the glitazones, which are insulin sensitizers acting by reducing insulin resistance through a reduction of free fatty acids in plasma. These drugs reduce rather than stimulate insulin secretion, as other drugs do (equivalent to exogenous insulin), and have been shown to reduce carotid artery intimal thickness $[15,16]$. The BARI II trial will test whether the effect of these drugs on coronary heart disease differs from that of SU or exogenous insulin.

In conclusion, the combination of diabetes and IHD is double jeopardy, and aggressive management of all risk factors for CVD as well as hyperglycemia should be undertaken in order to reduce the risk of new events of CVD. The choice of glucose-lowering drugs is at present less essential, although overweight patients should be urged to take metformin, and older SU should be avoided due to the risk of inhibiting preconditioning in the ischemic heart. Decisions to perform invasive therapy for IHD should rest on the same principles as for nondiabetics, but at present $\mathrm{CABG}$ should be considered preferable to angioplasty for the management of IHD. 


\section{References}

1 Haffner SM, et al: Mortality from coronary heart disease in subjects with type 2 diabetes and in nondiabetic subjects with and without prior myocardial infarction. $\mathrm{N}$ Engl $\mathrm{J}$ Med 1998;339:229-241.

2 Gustafsson I, Hildebrandt P, Seibæk M, Melchior T, Torp-Pedersen C, Køber L, KaiserNielsen $P$, and the TRACE Study Group: Long-term prognosis of diabetic patients with myocardial infarction: Relation to antidiabetic treatment regimen. Eur Heart J 2000;21: 1937-1943.

3 Hasdai D, Rizza RA, Grill DE, Scott CG, Garratt KN, Holmes DR Jr: Diabetes mellitus and outcome after successful percutaneous coronary revascularization: The Mayo Clinic experience 1979-1998. Heart Drug 2001;1:132137.

4 Hasdai D, Rizza RA, Grill DE, Scott CG, Garratt KN, Holmes DR Jr: Treatment of diabetes mellitus by diet alone versus oral hypoglycemics versus insulin and outcome after successful percutaneous coronary revascularization. Heart Drug 2001;1:138-143.

5 Chowdhury TA, Lasker SS, Dyer PH: Comparison of secondary prevention measures after myocardial infarction in subjects with and without diabetes mellitus. J Intern Med 1999; 245:565-570.
6 Schofer J, Schluter M, Rau T, Hammer F, Haag N, Mathey DG: Influence of treatment modality on angiographic outcome of coronary stenting in diabetic patients: A controlled study. J Am Coll Cardiol 2000;35:1554-1559.

7 The Diabetes Control and Complications Trial Research Group: The effect of intensive treatment of diabetes on the development and progression of long-term complications of insulindependent diabetes mellitus. N Engl J Med 1993;329:977-986.

8 UK Prospective Diabetes Study (UKPDS) Group: Intensive blood-glucose control with sulphonylureas or insulin compared with conventional treatment and risk of complications in patients with type 2 diabetes (UKPDS 33). Lancet 1998;352:837-853.

9 Ohkubo Y, Kishikawa H, Araki E, et al: Intensive insulin therapy prevents the progression of diabetic microvascular complications in Japanese patients with non-insulin-dependent diabetes mellitus: A randomized prospective 6year study. Diabet Res Clin Pract 1995;28: 103-117.

10 UK Prospective Diabetes Study (UKPDS) Group: Intensive blood-glucose control with metformin on complications in overweight patients with type 2 diabetes (UKPDS 34). Lancet 1998;352:854-865.

11 Martin DB: Atherogenicity of insulin. Diabetes Res Clin Pract 1988;4(suppl 1):58-61.
12 Garratt KN, Brady PA, Hassinger NL, Grill DE, Terzic A, Holmes DR Jr: Sulfonylurea drugs increase early mortality in patients with diabetes mellitus after direct angioplasty for acute myocardial infarction. J Am Coll Cardiol 1999;33:119-124.

13 The BARI investigators: Seven year outcome in the Bypass Angioplasty Revascularization Investigation (BARI) by treatment and diabetic status. J Am Coll Cardiol 2000;35:11221129.

14 Detre KM, Lombardero MS, Brooks MM, Hardison RM, Holubkov R, Sopko G, Frye RL, Chaitman BR: The effect of previous coronaryartery bypass surgery on the prognosis of patients with diabetes who have acute myocardia infarction. Bypass Angioplasty Revascularization Investigation Investigators. NEJM 2000; 342:989-997.

15 Kornowski R, Mintz GS, Kent KM, et al: Increased restenosis in diabetes mellitus after coronary interventions is due to exaggerated intimal hyperplasia. A serial intravascular ultrasound study. Circulation 1997;95:13661369.

16 Parulkar AA, Pendergrass ML, Granda-Ayala R, Lee TR, Fonseca VA: Nonhypoglycemic effects of thiazolidine diones. Ann Intern Med 200;2:134:61-71. 